\title{
A comparative study of feto-maternal outcome in expectant management versus active management in pre-labor rupture of membranes at term
}

\author{
Savitha T. S.*, Pruthvi S., Sudha C. P., Vikram S. Nadig
}

Department of Obstetrics and Gynecology, Kempegowda Institute of Medical Sciences, Bangalore, Karnataka, India

Received: 18 November 2017

Revised: 03 December 2017

Accepted: 18 December 2017

\author{
*Correspondence: \\ Dr. Savitha T. S., \\ E-mail: drsavithats@gmail.com
}

Copyright: (c) the author(s), publisher and licensee Medip Academy. This is an open-access article distributed under the terms of the Creative Commons Attribution Non-Commercial License, which permits unrestricted non-commercial use, distribution, and reproduction in any medium, provided the original work is properly cited.

\begin{abstract}
Background: Premature rupture of the membranes at term is spontaneous rupture of the membranes after 37 weeks of gestation and before the onset of the regular painful uterine contractions, complicates $5-10 \%$ of pregnancies, $80 \%$ of cases of PROM occur at term. It complicates the pregnancy leading to maternal and fetal complications, immediate risks such as cord prolapse, cord compression and placental abruptions, and later risks such as maternal or neonatal infection and the interventions such as caesarean section and instrumental vaginal delivery. These cases are either managed conservatively or by immediate induction of labour. Objective of present study is to compare the efficacy and safety of induction of labor versus expectant management at term PROM, in terms of maternal and fetal outcome. Methods: A randomized control trial of 100 women coming to KIMSH from $01 / 04 / 2015$ to $01 / 05 / 2016$ with PROM at term with duration of leak $\leq 6$ hours and a Bishop score $\leq 5$ were assigned to group A immediate induction group and group B expectant management group with 50 cases in each group.

Results: The mean interval from PROM to delivery was significantly shorter in the induction Group $15.62 \pm 4.97$ as compared with expectant group $17.58 \pm 4.78$. Incidence of maternal morbidity and neonatal morbidity was comparable in both the groups. Intrapartum complications and mode of delivery were similar in both groups.

Conclusions: Immediate induction of labour in cases of PROM at term using oral misoprostol resulted in shorter induction delivery interval and hospital stay. Maternal morbidity and neonatal morbidity was comparable in both groups. It is concluded that immediate induction is better than expectant management. With active management many patients delivered vaginally within 24 hours without increase in the Caesarean section rate and decreased the need for oxytocin augmentation.
\end{abstract}

Keywords: Induction delivery interval, Misoprostol, PROM

\section{INTRODUCTION}

Pre-labour rupture of the membranes (PROM) at term is defined as spontaneous rupture of the membranes after 37 weeks of the gestation before the onset of labor. PROM occurs in approximately $5-10 \%$ of all pregnancies, of which approximately $80 \%$ occur at term. ${ }^{1}$
In term PROM usually $70-80 \%$ goes into spontaneous onset of labor within 12 to 24 hours, and $95 \%$ within 48 to 72 hours. If the latent period exceeds 24 hours, the chances of infection increase. $^{2}$

PROM is a common and important event in obstetrics. It has a major impact on fetal and maternal outcome, 
complicating the pregnancy leading to maternal and fetal complications, immediate risks such as cord prolapse, cord compression and placental abruptions, and later risks such as maternal or neonatal infection, as well as the use of interventions such as caesarean section and instrumental vaginal delivery.

The major question regarding management of these patients is whether to allow them to enter labor spontaneously or to induce labor as there is a major risk of intrauterine infection which is a most serious complication associated with PROM for the mother and the neonate. But induction of labor in patient with unfavourable cervix is still a challenge.

Different methods of induction for cervical ripening like prostaglandins are available. However, there remains the risk of increased caesarean section due to either failure of induction or hyperstimulation. The chances of infection increase, if the latent period exceeds $24 \mathrm{hrs}$. Keeping these considerations, there was a tendency to induce labor at the earliest.

Early induction of labor helps in decreasing risk of chorioamnionitis, need for neonatal antibiotic therapy, neonatal intensive care (NICU) admission, and increased maternal satisfaction. Induction of labor is indicated, when it is agreed that the fetus or mother will benefit from delivery.

\section{METHODS}

100 pregnant women admitted in KIMSH with spontaneous rupture of membranes 37 completed weeks but not in labor meeting the inclusion and exclusion criterion was included.

\section{Methods of collection of data}

- A study of 100 cases of term Premature rupture of membrane (PROM). PROM was confirmed by sterile speculum examination of vagina

- Detailed history was taken as per study proforma

- General, abdominal and obstetric examination was carried out

- Routine and specific investigations was done including USG, TLC, DLC and vaginal swab for culture and sensitivity was sent on admission

- Those who met the eligibility criteria are invited to voluntarily participate in the study. Written informed consent was taken after explaining the aims and procedures.

- All the patients irrespective of duration of prom was given injectable antibiotics till delivery.

- Patients were randomly assigned to Group A (Active management) and Group B (Expectant management) 50 in each group

\section{Inclusion criteria}

- Singleton pregnancy

- Vertex presentation

- Gestational age $>37$ weeks

- Spontaneous PROM $\leq 6$ hours of duration

- $\quad$ Bishop score $\leq 5$

- Absence of active labor

\section{Exclusion criteria}

- Previous cesarean or major uterine surgery

- Cephalo-pelvic disproportion

- Oligohydramnios

- Patient with fetal distress and MSAF

- Pregnancy associated with complications like PIH, GDM, anemia, multiple pregnancies, $\mathrm{Rh}$ incompatibility, placenta previa, heart disease, asthma

- No features of chorioamnitis

- Preterm prom(PPROM)

- Known hypersensitivity to prostaglandins

\section{Active management (Group A)}

- After initial assessment, in the immediate induction group labor was induced with oral misoprostol 50 mcg 4th hourly maximum upto 6 doses. Depending on progress of labor, augmented with oxytocin drip if required.

- Patient were monitored for any hyperstimulation or tachysystole or hypertonus associated with fetal distress.

- Labor induction was considered successful, if women delivered within 24 hours of initiating induction method or if there was a definite change in cervical score after hours of induction.

- Any surgical intervention and cause for it was evaluated. Any complication arising during induction, labor or after delivery was noted.

- Maternal and fetal monitoring was done by using partographs.

- Immediate fetal outcome was monitored by the help of APGAR score.

\section{Expectant management (Group B)}

- Patients was kept under constant supervision. Maternal pulse, B.P and temperature was recorded 4th hourly. Patients were particularly observed for symptoms and signs of chorioamnitis.

- No unnecessary P/V examinations was carried out. $\mathrm{P} / \mathrm{V}$ whenever required was done maintaining strict aseptic measures.

- If patient fails to go into labor within 12 hours, reasessment of cervical findings was done and labor was augmented with oxytocin or induced with oral misoprostol $50 \mathrm{mcg}$ depending on Bishop score. 
- Patients were meticulously monitored during induction and labor as for group A case.

\section{RESULTS}

Maximum women were in the age group of 18-23 years (50\%). Age distribution in both the groups are statistically insignificant. Mean age distribution in group $\mathrm{A}$ is $23.50 \pm 3.22$ and mean age distribution in group $\mathrm{B}$ is $24.24 \pm 3.34$.

$58 \%$ belonged to low socio-economic status, and $42 \%$ belonged to middle socioeconomic status. In the study $62 \%$ were Primigravida and $38 \%$ were Multigravida.

Table 1: Time between PROM to admission.

\begin{tabular}{|llllll|l|}
\hline Time in & Group A & \multicolumn{3}{c|}{ Group B } & Total \\
hours & No & $\%$ & No & \% & \\
\hline$<2$ & 5 & 10 & 4 & 8 & $9 \%$ \\
\hline $2-4$ & 22 & 44 & 25 & 50 & $47 \%$ \\
\hline $4-6$ & 23 & 46 & 21 & 42 & $44 \%$ \\
\hline Total & 50 & 100 & 50 & 100 & $100 \%$ \\
\hline
\end{tabular}

$\mathrm{P}=0.834$, not significant, Chi-Square test

Maximum number of patients (44\%) reported between 4 to 6 hours after rupture of membranes.

Table 2: Bishop Score distribution at the time of admission.

\begin{tabular}{|llllll|}
\hline Bishop & Group A & \multicolumn{3}{c|}{ Group B } & Total \\
Score & No & \% & No & $\%$ & \\
\hline $0-2$ & 22 & 44 & 27 & 54 & $49 \%$ \\
\hline $3-5$ & 28 & 56 & 23 & 46 & $51 \%$ \\
\hline Total & 50 & 100 & 50 & 100 & $100 \%$ \\
\hline
\end{tabular}

$\mathrm{P}=0.317$, not significant, Chi-Square test

Maximum number of women (51\%) had Bishop score of 3 to 5 .

Table 3: Interpretation of Group A.

\begin{tabular}{|c|c|c|}
\hline Group A & No. of patients $(n=50)$ & $\%$ \\
\hline \multicolumn{3}{|c|}{ Induction delivery interval in hours } \\
\hline$<12$ & 23 & 46 \\
\hline $12-24$ & 24 & 48 \\
\hline$>24$ & 3 & 6 \\
\hline Need of Oxytocin & 9 & 18 \\
\hline \multicolumn{3}{|c|}{ PROM to delivery interval in hours } \\
\hline$<12$ & 3 & 6 \\
\hline $12-24$ & 41 & 82 \\
\hline$>24$ & 6 & 12 \\
\hline \multicolumn{3}{|l|}{ Mode of delivery } \\
\hline Vaginal & 42 & 84 \\
\hline LSCS & 8 & 16 \\
\hline
\end{tabular}

Among 50 patients in Group A 47 patients delivered (94\%) within 24 hours after induction, 9 patients required oxytocin, 42 had vaginal delivery $(84 \%)$ and 8 had caserean section $(16 \%)$.

Table 4: Interpretation of Group B.

\begin{tabular}{|lcc|}
\hline $\begin{array}{l}\text { Group B } \\
\text { Spontaneous delivery }\end{array}$ & No. of patients $(\mathbf{n = 5 0})$ & $\%$ \\
\hline $\begin{array}{l}\text { within } 12 \text { hours of } \\
\text { admission }\end{array}$ & 18 & 36 \\
\hline $\begin{array}{l}\text { Need for Oxytocin } \\
\text { Need for induction }\end{array}$ & 62 & 44 \\
\hline Admission delivery interval in hours & 12 \\
\hline$<12$ & 18 & 36 \\
\hline $12-24$ & 29 & 58 \\
\hline$>24$ & 3 & 6 \\
\hline PROM to delivery interval in hours & \\
\hline$<12$ & 3 & 6 \\
\hline $12-24$ & 36 & 72 \\
\hline$>24$ & 11 & 22 \\
\hline Mode of delivery & 41 & 82 \\
\hline Vaginal & 9 & 18 \\
\hline LSCS
\end{tabular}

Among 50 patients in Group B 18 delivered spontaneously within 12 hours after admission (36\%), after 12 hours of observation 22 patients required augmentation with oxytocin and 6 patients required induction. 41 patients had vaginal delivery $(82 \%)$ and 9 patients had caserean section (18\%). Rate of LSCS (16\%) and instrumental delivery (2\%) is similar in both the groups.

Table 5: Indication for caserean section.

\begin{tabular}{|c|c|c|c|c|c|}
\hline \multirow[t]{2}{*}{ Indications } & \multicolumn{2}{|c|}{$\begin{array}{l}\text { Group A } \\
(n=50)\end{array}$} & \multicolumn{2}{|c|}{$\begin{array}{l}\text { Group B } \\
(\mathrm{n}=50)\end{array}$} & \multirow{2}{*}{$\begin{array}{l}P \\
\text { value }\end{array}$} \\
\hline & No & $\%$ & No & $\%$ & \\
\hline Fetal distress & 05 & 10 & 03 & 06 & 0.715 \\
\hline MSAF & 02 & 04 & 03 & 06 & 1.000 \\
\hline Failure to progress & 01 & 02 & 03 & 06 & 0.617 \\
\hline
\end{tabular}

The main indications of caesarean section in induction group is fetal distress $(10 \%)$ where as in expectant group MSAF, Fetal distress, failure to progress contributed equally (6\% each).

Table 6: Comparison between induction delivery interval in group A and admission delivery interval in group $\mathbf{B}$.

\begin{tabular}{|lllll|}
$\begin{array}{l}\text { Delivery } \\
\text { interval in } \\
\text { hours }\end{array}$ & $\begin{array}{l}\text { Group A }(\mathrm{n}=50) \\
\text { (induction } \\
\text { delivery interval) }\end{array}$ & $\begin{array}{l}\text { Group B }(\mathrm{n}=50) \\
\text { (admission } \\
\text { delivery interval }\end{array}$ \\
\hline$<12$ & 23 & $\mathbf{\%}$ & $\mathbf{N o}$ & $\mathbf{\%}$ \\
\hline $12-24$ & 24 & 48 & 13 & 26 \\
\hline$>24$ & 03 & 06 & 03 & 68 \\
\hline Mean \pm SD & $11.60 \pm 5.32$ & & $13.66 \pm 4.82$ \\
\hline
\end{tabular}

$\mathrm{P}=0.105$, Not significant, Chi-Square test 
Delivery interval was shorter in induction group compared to expectant management group. Mean induction delivery interval in group $\mathrm{A}$ is $11.60 \pm 5.32$ hours and Mean admission delivery interval in group B is $13.66 \pm 4.82$ hours.

Table 7: Comparison of PROM to delivery interval in two groups of patients studied.

\begin{tabular}{|lllll|}
\hline $\begin{array}{l}\text { PROM to } \\
\text { delivery interval } \\
\text { in hours }\end{array}$ & $\begin{array}{l}\text { Grouj A } \\
(\mathbf{n = 5 0})\end{array}$ & No & \% & \multicolumn{2}{l|}{$\begin{array}{l}\text { Group B } \\
(\mathbf{n}=50)\end{array}$} & $\%$ \\
\hline$<12$ & 03 & 06 & 03 & 06 \\
\hline $12-24$ & 41 & 82 & 36 & 72 \\
\hline$>24$ & 06 & 12 & 11 & 22 \\
\hline Mean \pm SD & $15.62 \pm 4.97$ & $17.58 \pm 4.78$ \\
\hline
\end{tabular}

Not significant, $\mathrm{P}=0.408$, Chi-Square test

PROM to delivery was shorter in induction group (15.62 \pm 4.97$)$ compared to expectant management group $(17.58 \pm 4.78)$.

Table 8: APGAR score at 1 minute and 5 minute.

\begin{tabular}{|c|c|c|c|c|c|}
\hline \multirow{2}{*}{ Apgar score } & \multicolumn{2}{|c|}{$\begin{array}{l}\text { Group A } \\
(n=50)\end{array}$} & \multicolumn{2}{|c|}{$\begin{array}{l}\text { Group B } \\
(n=50)\end{array}$} & \multirow{2}{*}{$\begin{array}{l}P \\
\text { value }\end{array}$} \\
\hline & No & $\%$ & No & $\%$ & \\
\hline $\mathrm{APGAR}<7$ at $1 \mathrm{~min}$ & 02 & 04 & 01 & 02 & 01 \\
\hline APGAR $<7$ at 5 min & 0 & 0 & 0 & 0 & 01 \\
\hline
\end{tabular}

2 babies in induction group (4\%) and 1 baby in expectant group (2\%) had APGAR $<7$ at 1 minute.

Table 9: Maternal complications.

\begin{tabular}{|c|c|c|c|c|c|}
\hline \multirow{2}{*}{$\begin{array}{l}\text { Maternal } \\
\text { complications }\end{array}$} & \multicolumn{2}{|c|}{$\begin{array}{l}\text { Group } \\
\text { A }(n=50)\end{array}$} & \multicolumn{2}{|c|}{$\begin{array}{l}\text { Group B } \\
(n=50)\end{array}$} & \multirow{2}{*}{$\begin{array}{l}\mathbf{P} \\
\text { value }\end{array}$} \\
\hline & No & $\%$ & No & $\%$ & \\
\hline $\begin{array}{l}\text { Nausea, vomiting } \\
\text { and diarrohea }\end{array}$ & 05 & 10 & 02 & 04 & 0.436 \\
\hline Pyrexia & 02 & 04 & 01 & 02 & 1.000 \\
\hline Tachysystole & 02 & 04 & 0 & 0 & 0.495 \\
\hline Hyperstimulation & 0 & 0 & 0 & 0 & 1.000 \\
\hline Hypertonus & 0 & 0 & 0 & 0 & 1.000 \\
\hline Chorioamnitis & 0 & 0 & 0 & 0 & 1.000 \\
\hline PPH & 04 & 08 & 03 & 06 & 0.495 \\
\hline Puerperal pyrexia & 03 & 06 & 03 & 06 & 1.000 \\
\hline
\end{tabular}

Incidence of nausea, vomiting, diarrohea was higher in induction group. Tachysystole was noted in 2 patients in induction group. Pyrexia, PPH and puerperal pyrexia was similar in both the groups.

Incidence of neonatal sepsis (10\%), hyperbilirubinemia (6\%) and admission to NICU (14\%) was higher in expectant group.

Chi-square/ Fisher Exact test has been used to find the significance of study parameters on categorical scale between two or more groups, Non-parametric setting for Qualitative data analysis.

Table 10: Neonatal complications.

\begin{tabular}{|llllll|}
\hline \multirow{2}{*}{$\begin{array}{l}\text { Neonatal } \\
\text { complications }\end{array}$} & Aroup & \multicolumn{2}{l}{ Group B } & P \\
& No & \% & No & \% & value \\
\hline Admission to NICU & 05 & 10 & 07 & 14 & 0.538 \\
\hline Birth Asphyxia & 01 & 02 & 01 & 02 & 1.000 \\
\hline Hyperbilirubinemia & 01 & 02 & 03 & 06 & 0.617 \\
\hline RDS & 01 & 02 & 0 & 0 & 1.000 \\
\hline Neonatal Sepsis & 03 & 06 & 05 & 10 & 0.715 \\
\hline
\end{tabular}

\section{DISCUSSION}

PROM is not uncommon yet the management, even at term, the management is controversial and there is no standard protocol for management.

When a pregnancy reaches term, women normally expect labour to begin spontaneously, without medical or surgical assistance. However, for approximately $8 \%$ of women, the membrane ruptures but labour does not begin spontaneously within the next few hours. Because the risk of maternal and fetal infection is known to increase with increasing duration. In majority of the reports, where immediate induction with misoprostol was done, the latency period was significantly shorter, hence the duration of labor and hospitalization period were reduced. However, expectant management was another approach used where in, the operative intervention rate was lesser, without rise in the perinatal and maternal morbidity. Because of limited information available it was difficult to determine which approach is better and thus a clinical trial was called for.

This study was conducted to compare both maternal and neonatal outcome in patients with confirmed PROM at term after early induction of labour shortly after rupture of the membranes (within 6 hours) versus delayed induction 12 hours after expectant management of PROM using either oxytocin or misoprostol. One hundred patients were included in this study randomly assigned into two groups, 50 patients each.

The results of the present study showed no significant difference between the two groups as regard the age. The mean and standard deviation was 23.50 \pm 3.22 in Group A and 24.24 \pm 3.34 in Group B which is statistically not significant. These results are in agreement with results obtained by Ngai et al and was supported with similar finding obtained by Javaid et al and Lee et al. ${ }^{3-5}$

In the present study, about $36 \%$ of patients in the expectant group went into spontaneous labour within 12 hours. These results are similar to the results obtained by Hannah et al. (1996)6 and supported with similar finding obtained by Napgal et al and Shetty et al. ${ }^{7,8}$ Oxytocin was 
used in $18 \%$ of patients in the immediate induction group and in $44 \%$ of patients in the expectant management group for augmentation of labour after the onset of labour pain. This is similar to the results obtained by Chaudhuri Snehamay $\mathrm{C}$ et al who found that the rate of use of oxytocin during labor was $32.43 \%$ induction group and $82.14 \%$ in expectant group. ${ }^{9}$

The present study showed that mean time interval for PROM to delivery was shorter in induction group (15.62 \pm 4.97 hours) than expectant group (17.58 \pm 4.78 hours) where expectant management was done for 12 hours. This is similar to the results obtained by Chaudhuri Snehamay et al where the mean interval from PROM to delivery was $17.10 \pm 10.3$ hours in induction group and $21.63 \pm 10.3$ in expectant group where expectant management was done for $12-24$ hours. ${ }^{9}$

The results of the present study are also similar to the study conducted by Aqueela Ayaz et al wherein it was noted that the mean time interval for PROM to delivery was 11.6 hours in induction group as compared to 17 hours in expectant group. ${ }^{10}$

The present study showed that there was no significant difference in the incidence of caesarean section in induction group (16\%) and expectant group (18\%).

In a large randomized prospective trial of over 5000 women, Hannah et al, found no difference in the rate of cesarean section among immediate induction and conservative management groups. ${ }^{6}$

There were no significant differences in the neonatal complications between the two groups. These results are in accord with results obtained by Shetty et al and supported by results obtained by Javaid et al. ${ }^{4,8}$

These results are in accord with results obtained by Wing et al and reinforced by Shetty et al and supported by results obtained by Javaid et al. ${ }^{4,8,11}$ In the present study, the major causes of neonatal morbidity were neonatal sepsis, hyperbilirubinemia, respiratory distress syndrome and birth asphyxia. Regarding neonatal sepsis, the rate was $6 \%$ in induction group and $10 \%$ in expectant group which is statistically insignificant. This result was in accord with many studies that stated that neonatal infection rate is not significantly different between the immediate induction and the expectant groups. Recent studies Javaid et al supported this result. ${ }^{4}$ The mean duration of hospital stay was shorter in induction group

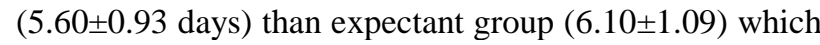
is statistically significant.

\section{Maternal morbidity}

There was no significant difference between the two groups.
The present study had no case of chorioamnionitis in both groups as the expectant management was done only for 12 hours. Ayaz A et al, concluded that chorioamnionitis is a serious complication resulting from expectant treatment because of increase interval between premature rupture of membranes and delivery. ${ }^{10}$

In another study conducted by Gibbs et al, found the higher rate of $(12 \%)$ chorioamnionitis in a conservatively managed group, while no patient case of induction with oral misoprostol developed chorioamnionitis. ${ }^{12}$ Incidence of puerperal pyrexia was same in both the groups $(6 \%)$. This result is also different from results obtained by Hannah et al. ${ }^{6}$ They stated that postpartum fever was less likely to develop in the immediate induction group; their results may be due to long expectancy period for 72 hours used in their study. This result is in accord with results obtained by Javaid et al who stated that there was no significant difference in the studied groups as postpartum fever was $1 \%$ in the immediate induction group and $1.8 \%$ in the expectant group. ${ }^{4}$

Other maternal complication is postpartum hemorrhage which was not significantly different between the studied groups. There were no maternal or neonatal mortalities. These results are in accord with results obtained by Wing et al and reinforced by Shetty et al. ${ }^{8,11}$

\section{CONCLUSION}

Immediate induction of labour in cases of PROM at term using oral misoprostol resulted in shorter induction delivery interval and hospital stay. Maternal morbidity and neonatal morbidity was comparable with induction and expectant line of management. It is concluded that immediate induction is better than expectant management. With active management many patients delivered vaginally within 24 hours without increase in the Caesarean section rate and it decreased the need for oxytocin augmentation. Oral misoprostol in a dose of 50 $\mu \mathrm{g}$ was effective and safe for induction, as there were no major maternal and neonatal drug related complications.

\section{Funding: No funding sources}

Conflict of interest: None declared

Ethical approval: The study was approved by the Institutional Ethics Committee

\section{REFERENCES}

1. Duff P. Premature rupture of membranes in term patients: induction of labour versus expectant management. Clin Obstet Gynecol. 1998;41:883-91.

2. Bennett KA, Butt K, Crane JM, Hutchens D, Young DC. A masked randomized comparison of oral and vaginal administration of misoprostol for labour induction. Obstet Gynecol. 1998;92 (4 pt 1):48-6.

3. Ngai SW, Chan YM, Lam SW. Labour characteristics and uterine activity: misoprostol compared with oxytocin in women at term with 
premature rupture of the fetal membranes. $\mathrm{Br} \mathrm{J}$ Obstet Gynecol. 2000;107(2):222-7.

4. Javaid K, Tahira T, Hassan S. Management prelabour rupture of the membranes at term, induction of labour compared with expectant mangment. Professional Med J. 2008;15(2):216-9.

5. Lee M, Park W, Yoon H. Early rupture of membranes after the spontaneous onset of labour as a risk factor for caesarian delivery. Eur J Obstet Gynecol Reprod Biol. 2009;148:152-7.

6. Hannah ME, Ohlsson A, Farine D. Induction of labour compared with expectant management for prelabour rupture of the membranes at term. $\mathrm{N}$ Eng $\mathrm{J}$ Med. 1996;334(24):1005-10.

7. Nagpal M, Monika B, Chitra R. Oral misoprostol versus intracervical prostaglandin E2 gel for active management of premature rupture of membranes at term. Int J Obstet Gynecol. 2009;106:23-6.

8. Shetty A, Stewart K and Stewarat G. Active management of term prelabour rupture of the membranes at term with oral misoprostol. $\mathrm{Br} \mathrm{J}$ Obstet Gynecol. 2002;109(6):645-50.

9. Snehamay C, Nath MS, Kumar BP, Sudipta B. Premature rupture of membranes at term: immediate induction with PGE2 gel compared with delayed induction with oxytocin. J Obstet Gynaecol India. 2006;56:224-9.

10. Ayaz A, Saeed S, Farooq MU, Ahmad F, Bahoo LA, Ahmad I. Pre-labour rupture of membranes at term in patients with an unfavorable cervix: active versus conservative management. Taiwan J Obstet Gynecol. 2008;47:2.

11. Wing DA, Paul R and Jones M. Induction of labour with misoprostol for premature rupture of the fetal membranes beyond thirty six weeks gestation. Am J Obstet Gynecol. 1998;179(1):94-9.

12. Gibbs RS, Blanco JD, St Clair PJ, Castaneda YS. Quantitative bacteriology of amniotic fluid from women with clinical intra-amniotic infection at term. J Infect Dis. 1982;145:1-8.

Cite this article as: Savitha TS, Pruthvi S, Sudha CP, Nadig VS. A comparative study of feto-maternal outcome in expectant management versus active management in pre-labor rupture of membranes at term. Int J Reprod Contracept Obstet Gynecol 2018;7:146-51. 